\title{
Penerapan Green Roof pada Perencanaan Gedung Olahraga Universitas Pembangunan Jaya
}

\author{
Bagas Makarim ${ }^{1}$, Elysa Damayanti ${ }^{1}$, Kevin Chrisvalliando $^{1}$, Tria Octa $^{1}$, Ryan Septiady ${ }^{2}$ \\ ${ }^{1}$ Program Studi Teknik Sipil, Universitas Pembangunan Jaya \\ ${ }^{2}$ Center for Urban Studies, Universitas Pembangunan Jaya \\ ryan.septiady@upj.ac.id
}

\begin{abstract}
The increasing of building constructions, and a lot of empty lands that used as a road construction has made few problems for environment and the surroundings. Green roof technology has shown as one of the sustainable design concept in the trial for reaching the goal which is a sustainable building that good for the environment. the function of using green roof to a building construction are various, one of the function is to be an open building for interaction, aesthetic elements for building, or only for the closed roof media. the application of green roof function will give an impact to a lot kind of things, such as a figure of landscape design, green roof type that will be used, and then an aspect of technical used.

Sport is an activity that could give a healthiness and happiness to a human being. Universitas Pembangunan Jaya is one of the University that has a lot of achievements from the students. that was one of the reason of the construction building of GOR. this sport building construction is hope to give a great positive impact to the development of sport achievements in Pembangunan Jaya University. Technically, there's a fact that green roof can give an impact to a building design from few pinpoints such as weighting, room availability for a layered green roof, drainage system, and also a watering problem in the garden. Green roof has given a lot of various advantages, such as an aesthetic elements to a building, a media for decreasing the hot temperature or radiation of sun, and also as a weather stabilizer in the surroundings.
\end{abstract}

Keywords : Building Concept, Green Roof, Gymnasium

\begin{abstract}
Abstrak : Meningkatnya pembangunan gedung-gedung, dan banyaknya lahan kosong yang digunakan untuk pembuatan jalan, telah menimbulkan masalah terhadap lingkungan di sekitarnya. Teknologi green roof muncul sebagai salah satu konsep sustainable design dalam upaya untuk mewujudkan suatu bangunan yang lebih ramah terhadap lingkungannya. Fungsi penggunaan green roof pada suatu bangunan cukup beragam, antara lain sebagai ruang terbuka untuk interaksi, elemen estetis pada bangunan, ataupun hanya sebagai media penutup atap saja. Penetapan fungsi green roof tersebut selanjutnya akan berpengaruh pada berbagai hal lainnya mulai dari wujud desain lanskep, tipe green roof yang akan digunakan, sampai pada aspek pelaksanaan dan keteknisannya. Olahraga merupakan kegiatan yang dapat memberikan kesehatan dan kesenangan kepada manusia. Universitas Pembangunan Jaya salah satu Universitas yang sedang memiliki banyak prestasi oleh mahasiswanya, dari hal tersebut menjadi alasan pembangunan Gedung Olahraga tersebut. Pembangunan Gedung Olahraga ini diharapkan dapat berdampak positif bagi perkembangan prestasi keolahragaan di Kampus Universitas Pembangunan Jaya.

Dalam segi teknis diperoleh fakta bahwa penggunaan green roof dapat memberikan pengaruh terhadap desain bangunan dalam beberapa hal meliputi pembebanan, penyediaan ruang untuk penempatan lapisan green roof, sistem drainase, hingga masalah pengairan pada tanaman. Dalam penggunaannya, green roof telah memberikan manfaat yang cukup beragam antara lain sebagai elemen estetis pada atap bangunan, media penurun radiasi panas sinar matahari, hingga sebagai stabilitator udara di sekitarnya.

Kata Kunci : Konsep Bangunan, Green Roof, Gedung Olahraga
\end{abstract}

\section{PENDAHULUAN}

Pada umumnya, gedung olahraga adalah sumber daya pendukung yang terdiri dari segala bentuk dan jenis peralatan serta perlengkapan yang digunakan dalam kegiatan olahraga. Gedung olahraga memiliki sumber daya pendukung yang terdiri dari tempat olahraga dalam bentuk bangunan di atasnya dan batas fisik yang statusnya jelas dan memenuhi persyaratan yang ditetapkan untuk pelaksanaan program kegiatan olahraga. 
Konsep green roof mulai muncul di Indonesia baru beberapa tahun belakangan ini. Konsep green roof sebenarnya merupakan turunan dari prinsip sustainability (keberlanjutan), yaitu kemampuan berbagai macam sumber daya di bumi ini berinteraksi dengan sistem budaya manusia dan ekonomi serta daya adaptasinya dalam menghadapi kondisi lingkungan yang pastinya terus berubah.

Secara umum lapisan green roof terdiri dari konstruksi atap, membrane waterproofing, drainase, media tanam dengan tebal hingga mencapai 2 meter, dan tanaman. Tanah yang digunakan biasanya memiliki komposisi butir-butir tanah liat yang ringan dan batu pecah. Jenis tanaman tidak hanya sebatas tanaman perdu, tetapi juga pohon besar sehingga mampu menghadirkan satu kesatuan ekosistem. Jenis tanaman disesuaikan dengan kondisi cuaca dan iklim setempat. Tanaman yang tahan dengan cuaca kering lebih cocok dipilih guna lebih menghemat biaya pengairan, walaupun sistem pengairan tetap diperlukan.

\section{Latar Belakang}

Salah satu ancaman terbsear pada bumi ini adalah global warming. Hal tersebut dapat terjadi karena penggunaan bahan bakar fosil yang berlebihan, sehingga meningkatnya gas karbon monoksida $(\mathrm{CO})$ dan gas karbon dioksida $\left(\mathrm{CO}_{2}\right)$. Efek rumah kaca yang berlebihan meningkatkan suhu bumi, dimana pantulan panas dari bumi tidak diteruskan ke luar angkasa, akan tetapi panas tersebut kembali ke bumi dan terperangkap. Selain itu, berkurangnya Ruang Terbuka Hijau yang beralih fungsi menjadi kawasan perumahan, industri, dan lainnya.

Pada saat awal perkembangan era industri, prinsip pembangunan yang ideal dapat dikatakan jika melindungi manusia dari ancaman alam. Seperti bangunan yang dapat melindungi manusia dari kondisi cuaca biasa hingga kondisi yang ekstrem. Hal tersebut menimbulkan dampak negatif terhadap lingkungan sekitar, karena pembangunan tidak mempertimbangkan faktor keselamatan alam.

Pembangunan

merupakan

kebutuhan dasar manusia yang akan terus berlangsung. Namun dampak negatif dari pembangunan mustahil untuk dihilangkan. Maka dari itu konsep pembangunan yang berkelanjutan mendesak untuk diterapkan. Dengan demikian konsep pembangunan yang ideal bergeser ke arah yang responsif terhadap isu lingkungan. Green Building merupakan atribut yang diperlukan untuk mencapai keseimbangan antara pembangunan manusia dengan lingkungannya yang berkelanjutan. Salah satu penerapan dari green building adalah konsep green roof.

Peralihan tata guna lahan dari area sawah menjadi bangunan pendidikan pada pembangunan Universitas Pembanguna Jaya, membuat Ruang Terbuka Hijau semakin berkurang. Oleh karena itu penerapan green roof pada pembangunan Gedung Olahraga di Universitas Pembangunan Jaya, sebagai salah satu upaya untuk mengoptimalkan Ruang Terbuka Hijau.

\section{Formulasi Masalah}

Pada penelitian ini, penulis akan memfokuskan pada bagaimana bangunan ramah lingkungan dengan konsep sustainability (keberlanjutan). Salah satunya adalah implementasi konsep green roof pada bangunan Gedung Olahraga Universitas Pembangunan Jaya. Sebagai salah satu langkah untuk mengoptimalkan Ruang Terbuka Hijau yang saat ini semakin terbatas.

\section{Tujuan}

Tujuan penulis dari penelitian ini adalah untuk mengetahui mengenai desain dan fungsi dari green roof pada implementasi bangunan Gedung Olahraga Universitas Pembangunan Jaya. Selain itu juga untuk mengetahui sejauh mana aplikasi green roof tersebut berpengaruh terhadap lingkungan sekitarnya. 


\section{Sistematika Penulisan}

Penulisan dari hasil penelitian dibagi menjadi beberapa bab yang saling berhubungan. Adapun urutan pada pembahasan ini sebagai berikut :

\section{- Abstrak}

Menjelaskan ringkasan dari isi sebuah jurnal yang ditujukan untuk membantu pembaca agar mudah untuk memahami tujuan dari penulisnya. Yaitu mengenai konsep gelanggan olahraga dan konsep green roof.

\section{- Pendahuluan}

Merupakan sebuah narasi singkat mengenai apa yang akan dibahas pada penulisan ini.

\section{- Latar Belakang}

Merupakan uraian singkat dari masalah dan solusi yang akan dibahas pada penulisan ini. Yaitu mengenai global warming, dengan solusi pembangunan yang berkelanjutan.

\section{- Formulasi Masalah}

Menjelaskan batasan permasalah yang akan dianalisis, agar pembahasan tidak melenceng keluar dari topik. Yaitu mengenai optimalisasi RTH di Universitas Pembangunan Jaya.

- Tujuan

Menjelaskan mengenai tujuan penulis melakukan analisis. Dan memiliki hubungan dengan judul jurnal. Yaitu implmentasi Green Roof pada gedung olahraga UPJ.

\section{- Kajian Pustaka}

Menjelaskan teori yang digunakan sebagai acuan dalam penelitian. Kajian teori yang digunakan merupakan teori yang berhubungan dengan tujuan analisa penelitian.

\section{- Metodelogi Penelitian}

Merupakan penjelasan prinsip dasar atau teknik yang diterapkan dalam proses penelitian.

\section{- Hasil Penelitian dan Analisis}

Menyajikan data hasil penelitian dapat berupa dasar teori, foto, grafik, maupun ilustasi. Dan hasil olahan dari formulasi masalah, tujuan, dan metodelogi penetian menjadi sebuah solusi yang kongkrit.

\section{- Kesimpulan}

Merupakan sebuah gagasan yang didapatkan dari hasil analisis. Selain itu, agar pembaca lebih mudah menangkap hasil analisis.

\section{- Daftar Pustaka}

Merupakan bagian akhir dari susunan sebuah jurnal yang menjadi rujukan dalam melakukan penelitian ini. Dengan berisikan nama pengarang, judul karangan, tahun terbit, dan lainnya.

\section{KAJIAN PUSTAKA}

Kebijakan pengembangan green building yang diatur dalam Peraturan Gubernur Nomor 38 Tahun 2012 berimplikasi pada pengembangan taman atap sebagai salah satu unsur bangunan gedung hijau. Potensi pengembangan RTH dalam bentuk taman atap sebagai RTH privat dapat dioptimalkan mengingat banyaknya pembangunan bangunan gedung baru yang diarahkan untuk memenuhi spesifikasi bangunan gedung hijau (Leni Pritika, 2013).

Suatu green roof adalah lapisan tanaman yang tumbuh di atas atap. Berbagai pohon dan vegetasi pada green roof melindungi permukaan atap serta menghilangkan panas dari udara (Putu Dera dan Happy Ratna, 2015).

Implementasi konsep green building merupakan salah satu penerapan dari konsep sustainabilitas, dimana dalam membangun harus memperhatikan sinergi modal manusia,modal sosial, modal fisik, modal keuangan dan modal alam. Karena itu dalam menerapkan konsep green building banyak sekali faktor yang diperhatikan, lingkungan hidup natural, keberlangsungan manusia sebagai individu, anggota masyarakat serta norma budaya yang dianut (Ratna Dewi, 2017).

Menurut Peraturan Daerah Kota Tangerang Selatan Nomor 15 Tahun 2011, Rencana Tata Ruang Wilayah Kota Tangerang Selatan Tahun 2011 - 2031. 
Pasal 43 ayat (1) Penyediaan RTH sebagaimana dimaksud dalam Pasal 41 huruf $\mathrm{b}$ untuk mencapai luas minimal 30 (tiga puluh) persen dari luas wilayah kota, dikembangkan RTH privat minimal 10 (sepuluh) persen dan RTH publik sebesar 20 (dua puluh) persen dari luas wilayah kota. Ayat (2) Penyediaan RTH privat sebagaimana dimaksud pada ayat (1), meliputi pekarangan rumah, perkantoran, pertokoan dan tempat usaha, kawasan industri, fasilitas umum, pergudangan, taman atap bangunan, lapangan golf dan RTH di dalam kawasan bandar udara khususdengan luas kurang lebih 1.471,9(seribu empat ratus tujuh puluh satu koma sembilan) hektar atau10 (Sepuluh) persen dari 14.719 (empat belas ribu tujuh ratus sembilan belas) hektar luas kota.

Sesuai peraturan daerah kota tangerang selatan nomor 15 tahun 2011 tentang rencana tata ruang wilayah kota Tangerang Selatan. Universitas Pembangunan Jaya memiliki kewajiban dalam penyediaan RTH (Ruang Terbuka Hijau) minimal 10 persen dari luas wilayah yang termasuk dalam RTH privat. Universitas Pembangunan Jaya mengalokasikan lahan seluas $150.000 \mathrm{~m} 2$ untuk pembangunan dalam jangka waktu 20 tahun kedepan.

Sehingga dalam penerapannya RTH akan direalisasikan dalam lahan seluas $15.000 \mathrm{~m} 2$. Hingga saat ini pembangunan pada gedung administrasi (gedung A) dan gedung perpustakaan (gedung B) sudah menggunakan lahan seluas $26.023 \mathrm{~m} 2$ termasuk ruang terbuka sekitar $5.398 \mathrm{~m} 2$. Sehingga, luas lahan yang dimiliki Universitas Pembangunan Jaya seluas $123.997 \mathrm{~m} 2$ dengan kewajiban RTH tersisa seluas $9.602 \mathrm{~m} 2$ atau masih tersisa sekitar 64\% dari luas RTH 15.000 $\mathrm{m} 2$.

\section{METODOLOGI PENELITIAN}

Penelitian ini menggunakan metode deskriptif kualitatif dengan menganalisa konsep green roof yang sudah diterapkan pada bangunan formal khususnya universitas yang berada di Indonesia.

Langkah awal yang dilakukan dalam penelitian ini dengan mencari beberapa informasi terkait literatur maupun data-data bangunan yang telah mengimplementasikan konsep green roof pada bangunannya.

Pencarian literatur dilakukan melalui website, jurnal, dan laporan penelitian mengenai konsep green roof. Dengan langkah selanjutnya menganalisa konsep tersebut agar dapat diimplementasikan pada pembangunan Gedung Olahraga. Analisis konsep green roof yang dilakukan pada penelitian ini dengan merangkum data dan penyajian data sehingga didapatkan kesimpulan yang sesuai dengan lingkup penelitian.

Data yang didapat pada kesimpulan akan diimplementasikan berdasarkan konsep green roof pada Gedung Olahraga Universitas Pembangunan Jaya yang berlokasi di Kota Tangerang Selatan, Banten.

\section{HASIL PENELITIAN DAN ANALISIS}

Perkembangan penduduk yang begitu pesat mengakibatkan dampak yang sangat berpengaruh terhadap bumi ini, kondisi dimana suhu bumi meningkat akibat emisi gas $\mathrm{CO} 2$, untuk itu perlu adanya pemodifikasian dari Teknologi modern agar menjadi ramah lingkungan. Berbagai macam riset dan percobaan yang terus di tingkat kan agar dapat membuat bumi bisa tetap terjaga keasrian nya.

Green roof merupakan sebuah konsep bangunan yang di tanami tumbuh tumbuhan yang mengacu pada konsep ramah lingkungan. Beberapa tujuan dari green roof tersebut antara lain, sebagai penyerap air hujan, menyediakan zona isolasi, menciptakan habitat pada satwa liar, membantu meredakan polusi udara dan suara dan juga mengurangi efek dari pemanasan global. 
Green roof terbagi menjadi dua jenis, yaitu atap intensif dan atap luas. Konsep dari green roof merupakan salahsatu strategi yang efektif jika berkembang di Indonesia. Namun demikian, terdapat beberapa kendala penerapan Teknologi tersebut di negara kita, yaitu: Terbatasnya jumlah tenaga ahli di Indonesia yang mampu melakukan instalasi green roof dan juga sebagian besar masyarakat Indonesia tidak dapat menyanggupi instalasi serta perawatan green roof tersebut.

Element dan juga desain yang digunakan untuk membuat green roof juga di perhatikan sangat di perhatikan dalam pemilihannya, karena perlu memperhatikan aspek-aspek dalam melindungi, menghemat, mengurangi penggunaan sumber daya alam dan juga mutu dari kualitas udara di dalam ruangan itu sendiri.

Universitas Pembangunan Jaya yang berlokasi di Kota Tangerang Selatan, Bintaro merupakan salah satu Universitas swasta yang di dirikan pada tahun 2011 dibawah naungan Jaya Group. Rencana penerapan green roof di kampus ini bertujuan untuk membuat Ruang Terbuka Hijau di Kawasan kampus, serta membangun suatu bangunan yang ramah lingkungan dan juga membuat rasa nyaman serta estetika nya suatu bangunan.

Pembangunan yang akan dilakukan untuk penerapan Green Roof sendiri adalah dengan membangun gedung olahraga sebagai salah satu bangunan ramah lingkungan, yang akan difungsikan sebagai tempat penyalur bakat untuk mahasiswa/i Universitas Pembangunan Jaya.

Kurangnya ruang terbuka pada Kawasan ini perlu adanya strategi khusus untuk perancangan, pengoptimalan dan pencahayaan dan penghawaan alami pada desain bangunan gedung. Langkah yang diambil sebagai pengoptimalan RTH yaitu dengan memanfaatkan atap bangunan sebagai RTH. Lapisan green roof yang akan diaplikasikan terdiri dari tanaman, tanah, filter fabric, lapisan, drainase, water proof, membran, dan atap.
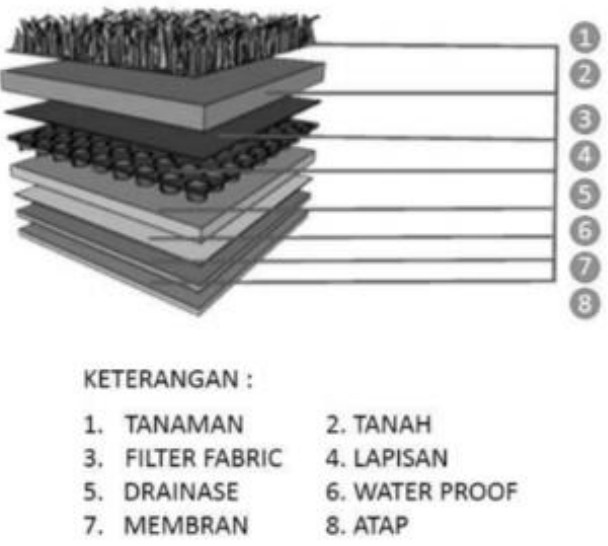

Gambar 1. Lapisan Green Roof

Selanjutnya, akan dibahas mengenai desain bangunan lainnya yang akan menggunakan konsep bangunan ramah lingkungan. Diantanya pada bagian atap, serta pemilihan dinding bangunan yang dapat menghemat listrik dengan memanfaatkan sumber daya alam yang ada.

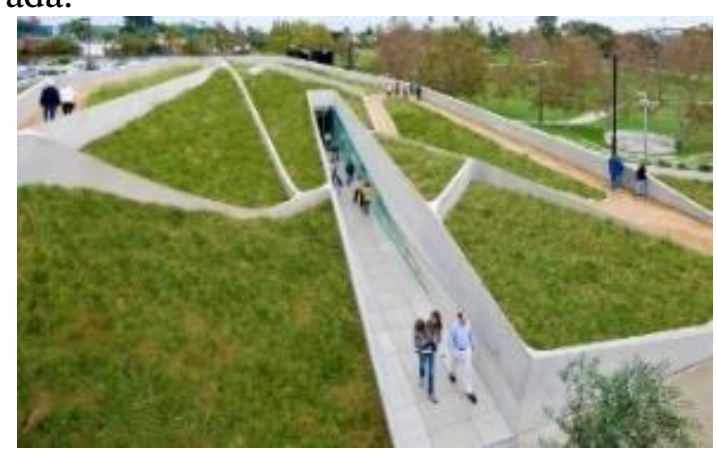

Gambar 2. Contoh Konsep Green Roof

Konsep green roof yang akan di aplikasikan pada gedung olahraga Universitas Pembangunan Jaya berkaca pada gambar disamping, dimana pada bagian atap akan dibuat ruang terbuka hijau. Pencahayaan dan penghawaan alami pada gedung ini yaitu dengan penggunaan roster pada dinding koridor. Dengan demikian dapat menghemat energy karena 
angin dan cahaya matahari yang masuk melalui lubang-lubang.

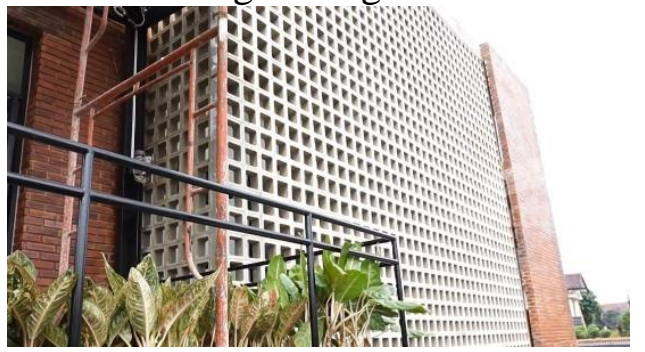

Gambar 3. Apliksi Dinding Roster

Seperti gambar diatas contoh roster yang akan digunakan pada gedung olahraga Universitas Pembangunan Jaya.

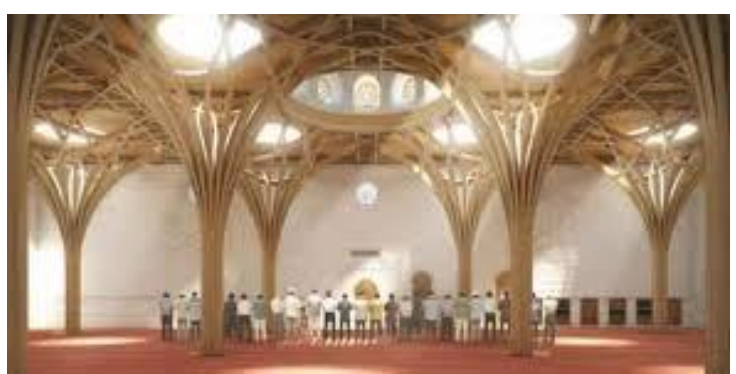

Gambar 4. Sustainable Roof

Selain memanfaatkan roster sebagai pencahayaan, serta pertukaran udara, akan di desain pada atap bagunan seperti gambar diatas, agar pencahayaan di dalam gedung dapat masuk secara optimal. Jadi untuk desain atap bangunan sendiri tidak full dengan tanaman namun pada bagian tengah akan dibentuk lubang yang dilapisi kaca agar cahaya dapat masuk ketika panas, namun tetap tertutup ketika hujan tiba.

Untuk layout bagian dalam gedung, bangunan ini terdiri dari 1 (satu) lapangan yang dapat dipakai sebagai lapangan basket, futsal serta bulu tangkis. Selain lapangan akan dibangun beberapa kursi penonton dibeberapa sisi lapangan.

Ruangan yang disediakan diantaranya ruang toilet, ruang ganti pakaian, ruang tunggu, 2 (dua) ruang basecamp, dan ruang 1 (satu) auditorium.

Ukuran lahan yang akan dibuat itu adalah $94.46 \mathrm{~m} \times 75.57 \mathrm{~m}$, dengan ukuran bangunan yang di bangun adalah $64 \mathrm{~m} \times$ $48.64 \mathrm{~m}$. Didalamnya terdapat parkiran mobil dan motor dan ditanam banyak pohon disekeliling gedung olahraga tersebut.
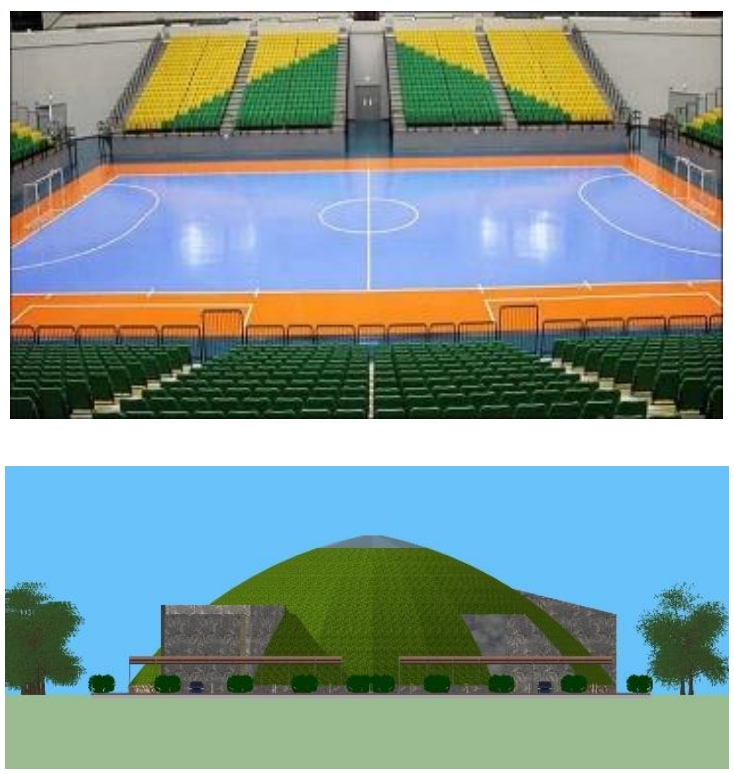

Gambar 5. Konsep Gedung Olahraga

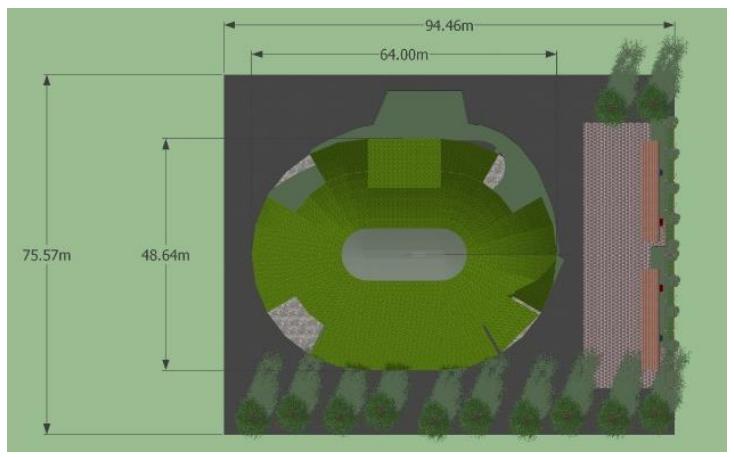

Gambar 6. Ukuran Lahan dan Bangunan

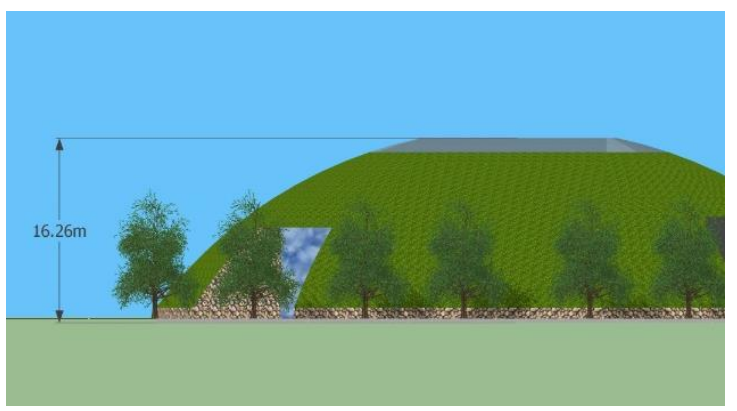

Gambar 7. Ukuran Tinggi Bangunan

Ukuran tinggi bangunan pada perencanaan gedung olahraga ini adalah setinggi $16.26 \mathrm{~m}$ dari elevasi 0.0 
Dengan kewajiban yang masih dimiliki, pembangunan gedung olahraga ini akan menambah kewajiban RTH sekitar $3.081 \mathrm{~m}^{2}$ atau $20 \%$ dari jumlah total RTH. Didapatkan luas total RTH dibangun seluas $8.470 \mathrm{~m} 2$ dan luas lahan RTH tersisa sekitar $6.530 \mathrm{~m}^{2}$ atau $44 \%$ dari luas lahan $15.000 \mathrm{~m}^{2}$.

Jadi pada pembangunan gedung olahraga ini konsep SED di implementasikan pada bagian atap dan dinding bangunan.

\section{KESIMPULAN}

Pemilihan pemodelan dengan metode Green Roof dapat menyelesaikan permasalahan RTH pada Kawasan Universitas Pembangunan Jaya. Adapun kelebihan lain menggunakan green roof, yaitu untuk menahan panas sinar matahari, menyerap air hujan, serta membantu mengisolasi bangunan dari polusi udara.

Dengan ini banyak manfaat yang didapatkan baik pengelola kampus maupun lingkungan sekitar karena arsitektur hijau merupakan arsitektur yang minim mengonsumsi sumber daya alam serta minim menimbulkan dampak negatif bagi lingkungan, yang merupakan langkah untuk merealisasikan kehidupan manusia yang berkelanjutan.

\section{DAFTAR PUSTAKA}

1. Jaya, U. P. (2017). Sejarah Identitas dan Nilai. Obtenido de www.upj.ac.id: https://www.upj.ac.id/staticpage/57/sejarah-identitas-dan-nilai

2. Menteng, R. A. (2012). Investigasi kinerja termal green roof sebagai pendingin pasif di iklim tropis. Depok: Fakultas Teknik Universitas Indonesia.

3. Nur'ain, R. D. (2017). Analisis Konsep Green Roof Pada Kampus School Of Art, Design And Media Ntu Singapore Dan Perpustakaan Ui Depok. NALARs Jurnal Arsitektur, 161-168.
4. Nur'aini, R. D., Hantono, D., Razak, A., \& Musyafa, A. (2017). Aplikasi Green Roof Pada Bangunan Marina Barrage Singapore. 1-6.

5. Peraturan Daerah Kota Tangerang Selatan. (2011). Obtenido de www.jdih.setjen.kemendagri.go.id: http://www.jdih.setjen.kemendagri.go. id/files/KOTA_TANGERANG\%20SE LATAN_15_2011.pdf

6. Sari, L. P. (2013). Studi Potensi Taman Atap Untuk Meningkatkan Luasan Rth Kota. Bogor: Institut Pertanian Bogor. 